Voix et Images

voixetimages

\title{
Voyage de Pehr Kalm au Canada en 1749
}

\section{Robert Lahaise}

Volume 3, numéro 3, avril 1978

Pierre Perrault

URI : https://id.erudit.org/iderudit/200128ar

DOI : https://doi.org/10.7202/200128ar

Aller au sommaire du numéro

Éditeur(s)

Les Presses de l'Université du Québec

ISSN

0318-9201 (imprimé)

1705-933X (numérique)

Découvrir la revue

Citer cet article

Lahaise, R. (1978). Voyage de Pehr Kalm au Canada en 1749. Voix et Images, 3(3), 487-490. https://doi.org/10.7202/200128ar d'utilisation que vous pouvez consulter en ligne.

https://apropos.erudit.org/fr/usagers/politique-dutilisation/ 


\section{Voyage de Pehr Kalm au Canada èn 1749}

Si la France "des lumières" peut s'offrịr au milieu du xvIII siècle une Encyclopédie, ou Dictionnaire raisonné des sciences, des arts et. des métiers en trente-trois volumes, la Suède pour sa part, plus modeste, fournit quand même une synthèse des connaissances de l'époque en botanique.

En effet, Charles Linné (1707-1778) - père de la classification binaire (par genres et par espèces) encore utilisée de nos jours - fait financer par le roi et l'Académie de Stockholm l'envoi de botanistes à travers le monde pour la réalisation de ses Systema naturae, Genera Plantarum et Species Plantarum.

Et c'est ainsi que des naturalistes suédois s'aventurent alors aussi bien aux Indes qu'en Amérique du' Sud ou en Palestine. Quant à l'Amérique septentrionale, c'est Pierre (Pehr) Kalm (1716-1779) qu'on choisit pour dresser l'inventaire de sa flore.

Parvenu en Nouvelle-Angleterre en septembre 1748, Kalm quitte Albany le 21 juin de l'année suivante pour y être de retour quelque quatre mois plus tard, le 29 octobre. Entre-temps, il aura connu de la. NouvelleFrance - au coût de 1404 livres 12 sols 6 deniers défrayé par le savant 
gouverneur La.Galissonière et le somptuaire Bigot - les lacs Saint-Sacrement et Champlain, le Richelieu, ainsi que les gouvernements de Montréal, Trois-Rivières et Québec jusqu'aux Éboulements. De ce périple canadien, il aura rapporté un peu plus de $\mathbf{4 0 0}$ pages de notes manuscrites sur un total de 1057 rédigées pour l'ensemble de son voyage. En 1753, il fait paraître à Stockholm son En Resa til Norra America ("Un voyage en Amé,rique du Nord ") en trois volumes, dont le dernier est consacré à la Nouvelle-France.

En 1880, L.-W. Marchand, juriste québécois, traduisait en 237 pages ayant éliminé nombre de passages qu'il jugeait sans intérêt - ce “Voyage " a partir de traductions anglaise et hollandaise provenant d'une traduction allemande faite sur l'original suédois... Notre «créateur de l'ethnographie canadienne-française» (xcii) méritait mieux!

C'est pourquoi le père Guy Béthune, o.p. - lecteur de français à I'Université d'Helsinki - traduisait intégralement la partie du manuscrit de Kalm consacrée au Canada, totalisant cette fois 607 pages pour la présente édition.

Préparée de longue date par ce grand humaniste que fut l'ethnobotaniste Jacques Rousseau, l'actuelle étude a été complétée et terminée par Pierre Morisset, professeur de biologie à l'Université Laval. II est toujours difficile de parachever le travail d'un prédécesseur, et le présent ouvrage s'en ressent quelque peu: les notes prévues par Rousseau sont inexistantes, mais se retrouvent quand même numérotées - sans ordre apparent - dans le texte de Kalm; l'index n'est relatif qu'au “Voyage» et non aux études qui le précèdent; le système de références par astérisques devient particulièrement ardu lorsqu'on en a jusqu'à six dans la même page (lxiii); on retrouve en outre quelques rares coquilles (Ixxi, 12, 152 , $230,276,322,419,439,541$ ) perdues dans le volume.

Malgré ces remarques - d'importance très secondaire - nous devons savoir gré à l'éditeur de ne pas avoir attendu davantage pour nous offrir ce récit de Kalm. II est toujours regrettable - sous prétexte d'une impossible perfection - de priver le public d'œuvres capitales. Et celle de Kalm, pour nous, Québécois, en est assurément une.

Scientifiquement et amoureusement introduit par Rousseau, le récit du Suédois (qui parlait également français, anglais et latin) présente un survol global de ce que nous étions vers la fin du régime français. II offre en outre un double avantage sur d'autres récits de ses contemporains: une objectivité sans doute supérieure due à la nationalité de son auteur, et la comparaison fréquente entre colons français et anglais, pratiquement interdite aux voyageurs de ces deux nations ennemies.

Ainsi, nous est-il loisible d'apprendre que, entre autres... 
- les Français sont en général bien plus portés vers les choses religieuses et la prière que les Anglais et les Hollandais... (169)

- un certain nombre de femmes sont assez paresseuses, imitant en cela les Anglaises: elles restent assises sur une chaise en regardant en l'air et en ne faisant rien... (380)

- les dames de Montréal semblent être plus jolies que celles de Québec [... et] lorsqu'elles appartiennent à la haute société, [elles] surpassent de beaucoup les secondes dans le domaine de la chasteté [...], la femme de Québec est en général aussi paresseuse qu'une Anglaise et bien plus portée qu'elle encore sur les questions sentimentales... (441)

- entre l'extrême politesse dont j'ai bénéficié ici [à Montréal] et celle des provinces anglaises, il y a toute la différence qui sépare le ciel et la terre... (182)

- les nobles d'ici s'intéressent davantage et prennent plus de plaisir à l'Histoire naturelle et au savoir que les colons anglais en général. La plupart de ceux-ci s'exilent afin de s'enrichir et de se remplir les poches et ne considèrent le savoir que comme une amusette... (85). [Comme le proclamera sereinement Monseigneur LouisAdolphe Paquet un siècle et demi plus tard: "Notre mission est moins de manier des capitaux que de remuer des idées "...!!!]

- je n'ai pas rencontré de gens qui soient aussi drôles qu'eux, toujours gais et de bonne humeur, profondément courageux et qui tiennent que rien n'est impossible à surmonter... (413)

- tous, ici, tiennent pour assuré que les gens du commun parlent ordinairement au Canada un français plus pur qu'en n'importe quelle Province de France et qu'ils peuvent même, à coup sûr, rivaliser avec. Paris. Ce sont les Français nés à Paris eux-mêmes, qui ont été obligés [...! de le reconnaître... (540)

et qu'enfin...

- les gens du commun au Canada, sont plus civilisés et plus ingénieux qu'en n'importe quel autre endroit du monde où je me suis rendu... (545)

Ne croirait-on pas retrouver, un demi-siècle plus tard, une filiation directe dans cette remarque du voyageur Francis Hall: "The Canadian peasant is still the same unsophisticated animal whom we may suppose to have been imported by Jacques Cartier." (Travels in Canada, and the United States, in 1816 and 1817, 42-43)?...

Bref, tous ces extraits, non choisis au hasard..., n'illustrent que la facette la plus colorée de l'œuvre, mais certes pas la plus importante. En effet, si un lecteur désire savoir de façon globale comment vivaient nos ancêtres il y a deux siècles, il trouvera réponse à tout dans ce volume: l'habitation, l'habillement, la nourriture, la religion, les distractions, le luminaire, les relations avec les Amérindiens, les moyens de transport, etc., autant de points traités par Kalm de façon quasi exhaustive. 
Sans doute, existe-t-il d'autres témoignages sur cette période de notre histoire avant la Conquête - je pense entre autres à ceux d'élisabeth Bégon l'épistolière ou de Louis Franquet le colonialiste... - mais il n'en est aucun fournissant un aperçu aussi complet que celui de Kalm.

Heureuse époque où on pouvait encore croire à une Nouvelle-France qui serait un jour "la Rome des provinces anglaises" (422) et où - tout comme dans le Céleste Empire où étaient promus les lettrés - notre gouverneur La Galissonnière récompensait ses militaires-herboristes... Toynbee enfin compris!

Robert Lahaise Université du Québec à Montréal

1. Traduction annotée du journal de route par Jacques Rousseau et Guy Béthune avec le concours de Pierre Morisset, Montréal, Le Cercle du Livre de France, 1977, clxv $+674 p$. 